\title{
Pyopericarditis and tropical pyomyositis: unusual concomitance
}

\author{
Pedro Henrique Magalhães Craveiro de Melo ${ }^{a}$, Henrique Lane Staniak ${ }^{a}$, \\ Aloísio Felipe-Silvab, Itamar Souza Santos ${ }^{a}$, Márcio Sommer Bittencourta
}

Melo PHMC, Staniak HL, Felipe-Silva A, Santos IS, Bittencourt MS. Pyopericarditis and tropical pyomyositis: unusual concomitance. Autopsy Case Rep [Internet]. 2012;2(1):49-53. http://dx.doi.org/10.4322/acr.2012.008

\section{ABSTRACT}

The authors report a case of a 19-year-old male who presented to the emergency room complaining of chest pain. His physical examination was unremarkable, but the EKG showed PR deviation and ST segment elevation. The patient was diagnosed as probable viral pericarditis and was prescribed oral anti-inflammatories. After 3 days he returned, complaining of chest pain worsening, generalized muscle pain and fever. Laboratory examinations showed creatine kinase isoenzyme $\mathrm{MB}(\mathrm{CK}-\mathrm{MB})=89.5 \mathrm{ng} \cdot \mathrm{mL}^{-1}$ and C-Reactive Protein $(\mathrm{CRP})=391 \mathrm{mg} \cdot \mathrm{L}^{-1}$. Echocardiogram showed pericardial thickening but no pericardial effusion was present. During admission the patient evolved with cardiac tamponade. Empirical ceftriaxone and oxacillin were started and the patient underwent pericardial surgical drainage. Staphylococcus aureus was isolated from the pericardial effusion. After 7 days the patient started complaining of leg pain, and fever recurred. Computed tomography of the lower limbs identified large muscle commitment compatible with the presence abscesses. These findings were suggestive of staphylococcal tropical myositis. The patient was treated with abscesses drainage and oxacillin. He was discharged after 18 days to complete oral antibiotic therapy.

Keywords: Pericarditis; Chest pain; Tropical myositis; Staphylococcus aureus.

\section{CASE REPORT}

A 19-year-old male patient, previously healthy, sought the emergency medical service complaining of a one-day chest pain of sudden onset. He referred worsening of the symptom with breath movements and supine position. He had a history of upper airway infection one week prior to hospital presentation. Physical examination on admission was normal. The electrocardiogram revealed the presence of sinus tachycardia, PR segment deviation and upsloping ST segment elevation (Figure 1). The echocardiogram, serum determination of troponin and CK-MB were normal. White blood cell count was $11200 / \mathrm{mm}^{3}$ (reference value $=4400-11300 / \mathrm{mm}^{3}$ ) and CRP $=24 \mathrm{mg} \cdot \mathrm{L}^{-1}$ $(\mathrm{RV}<5)$. He was discharged after 24 hours of observation with complete relief of pain, with the presumptive diagnosis of uncomplicated viral pericarditis and was prescribed non-steroidal antiinflammatory for seven days.

\footnotetext{
a Department of Internal Medicine - Hospital Universitário - Universidade de São Paulo, São Paulo/SP - Brazil.

${ }^{b}$ Anatomic Pathology Service - Hospital Universitário - Universidade de São Paulo, São Paulo/SP - Brazil.
} 


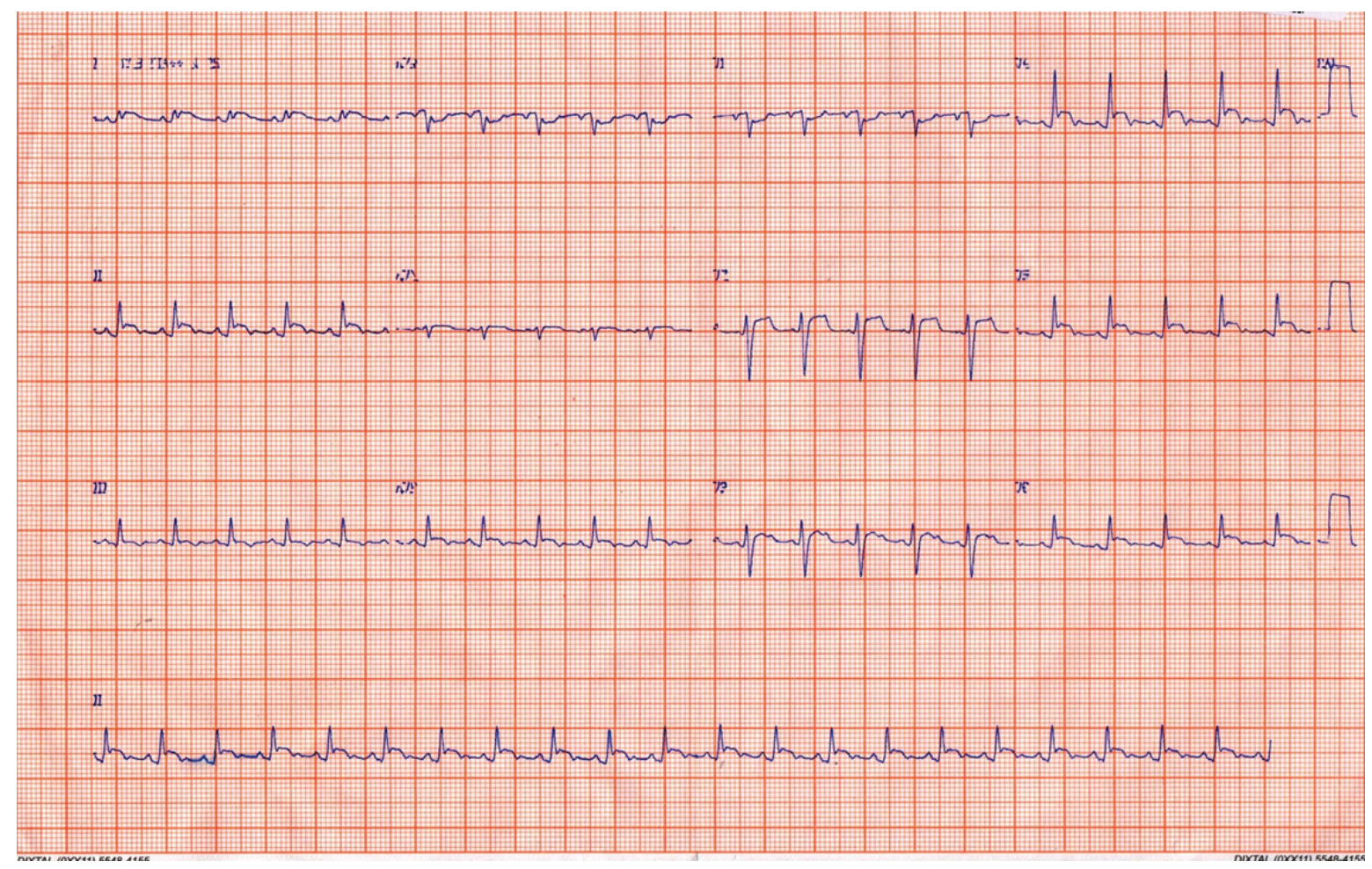

Figure 1 - EKG showing sinus rhythm, heart rate= $136 \mathrm{bpm}, \mathrm{PR}$ interval 0,10 ms, SÂP axis +60 $0^{\circ}$ SÂQRS axis $+60^{\circ}$, diffuse upsloping ST segment elevation seen best here in leads I, II, aVF, and V2 to V6, There is also subtle PR segment deviation (positive in aVR, negative in I, II, III, aVF and V3 to V6).

The patient returned to the hospital after 72 hours, complaining of worsening symptoms, fever and generalized myalgia. On physical examination he was acutely ill looking, wasted, and febrile. His hemodynamic parameters were stable and the heart and lung examination were normal. Laboratory tests on readmission revealed white blood cell count $=22.000 / \mathrm{mm}^{3}$ with a shift to the left, CK-MB = $89.5 \mathrm{ng} \cdot \mathrm{mL}^{-1}\left(\mathrm{RV}<5 \mathrm{ng} \cdot \mathrm{mL}^{-1}\right)$, $\mathrm{CRP}=391 \mathrm{mg} \cdot \mathrm{L}^{-1}\left(\mathrm{RV}<5 \mathrm{mg} \cdot \mathrm{L}^{-1}\right)$, erythrocyte sedimentation rate $(E S R)=44 \mathrm{~mm}(R V<15 \mathrm{~mm})$ in the first hour, the echocardiogram was repeated and showed the presence of pericardial thickening with no effusion nor signs of cardiac tamponade.

On the second day of readmission, the patient was septic and presented clinical signs of pericardial tamponade, which was treated by pericardial surgical drainage and biopsy. The procedure resulted in 250 milliliters output of pus. He was transferred to the ICU with clinical signs of septic shock demanding ventilatory and hemodynamic support and was prescribed ceftriaxone and oxacillin.

Further tests were carried out and the results were negative for HIV and EBV serologies, ANA and antids-DNA, determination ofC3and C4 werenormal. The pericardial fluid analysis revealed the presence of Gram-positive spherical bacteria. The search for fungus and acid fast bacilli (AFB) was negative and the culture isolated Staphylococcus aureus oxacillin sensitive. The pathological report was consistent with acute fibrinous pericarditis (Figure 2).

On the seventh day of hospitalization, the patient complained of pain and swelling in the right thigh and fever persisted. Computed axial tomography of the lower limbs identified multiple hypoatenuating images compatible with abscesses involving the muscles: gluteus maximus, gluteus medius (Figure 3 ) as well as the muscles: biceps femoris, sartorius, rectus femuris, vastus lateralis, vastus medialis some of them bilaterally (Figure 4).

The puncture of theses lesions disclosed the presence of purulent secretion. Staphylococcus aureus was also isolated from this site of infection leading to the diagnosis of staphylococcal pyomyositis.

After surgical drainage of the abscesses and maintenance of antibiotic therapy the patient presented no further fever. A new transthoracic echocardiography demonstrated improvement of the pericardial lesion as well as no additional valvar lesions. 
He was discharged on the eighteenth day of hospitalization with the prescription of prolonged oral antibiotic.

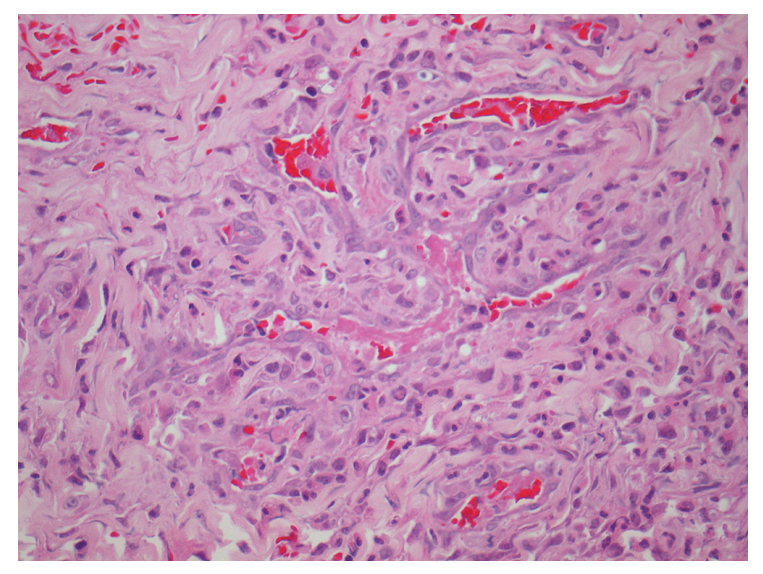

Figure 2 - Photomicrography (HE 400X) - fragment of pericardial tissue - presence of acute exudate with fibrin, polymorphonuclear leukocytes and reactive mesothelial hyperplasia - Acute fibrinous pericarditis.

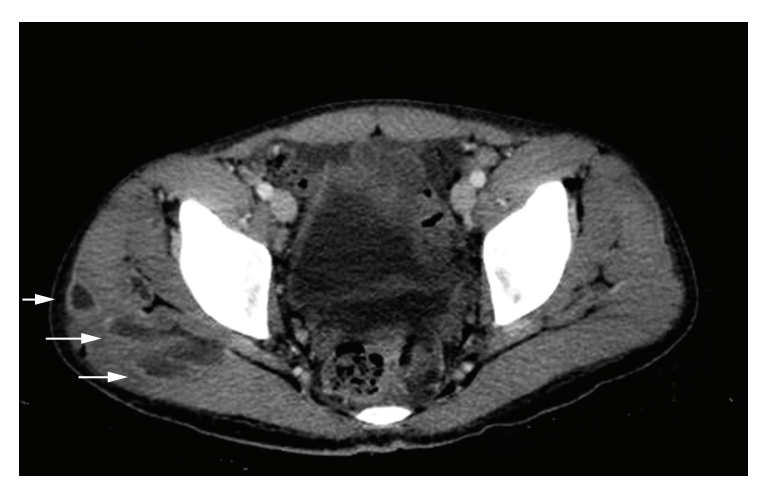

Figure 3 - Axial computed tomography of the pelvis showing increased volume of the gluteus muscles due to edema and hypoatenuating lesions compatible with abscess.

\section{DISCUSSION}

Viral pericarditis accounts for most cases of acute pericarditis, occurring predominantly in young individuals, usually preceded by upper respiratory infection. It is characterized by a benign course and usually the treatment consists in the use of nonsteroidal anti-inflammatories.

Although less frequent, infection by other agents such as: bacteria, fungi, tuberculosis bacillus; autoimmune, systemic diseases and cancer have to be considered in the differential diagnosis of acute pericarditis.

The bacterial pericarditis is an uncommon condition in the current medical practice, usually associated with predisposing factors as immunosuppression and infection of the bloodstream.

Nowadays, the purulent pericarditis is an uncommon diagnosis. Pyogenic pericarditis accounts for 0.7 to $1.0 \%$ of all cases of acute pericarditis. In a retrospective Spanish study of acute pericarditis there were found 33 cases of pyogenic pericarditis in a period of 19 years of study among a population of 593,600 people. ${ }^{1}$

In the antibiotics era bacterial pericarditis are associated with predisposing factors or diseases such as collagenosis, uremia and malignancies in $78 \%$. The development of bacterial pericarditis may occur by: hematogenous dissemination, contiguity with infectious foci on chest or sub diaphragmatic space, direct trauma or thoracic surgery and by continuity of a myocardium abscess. ${ }^{2}$
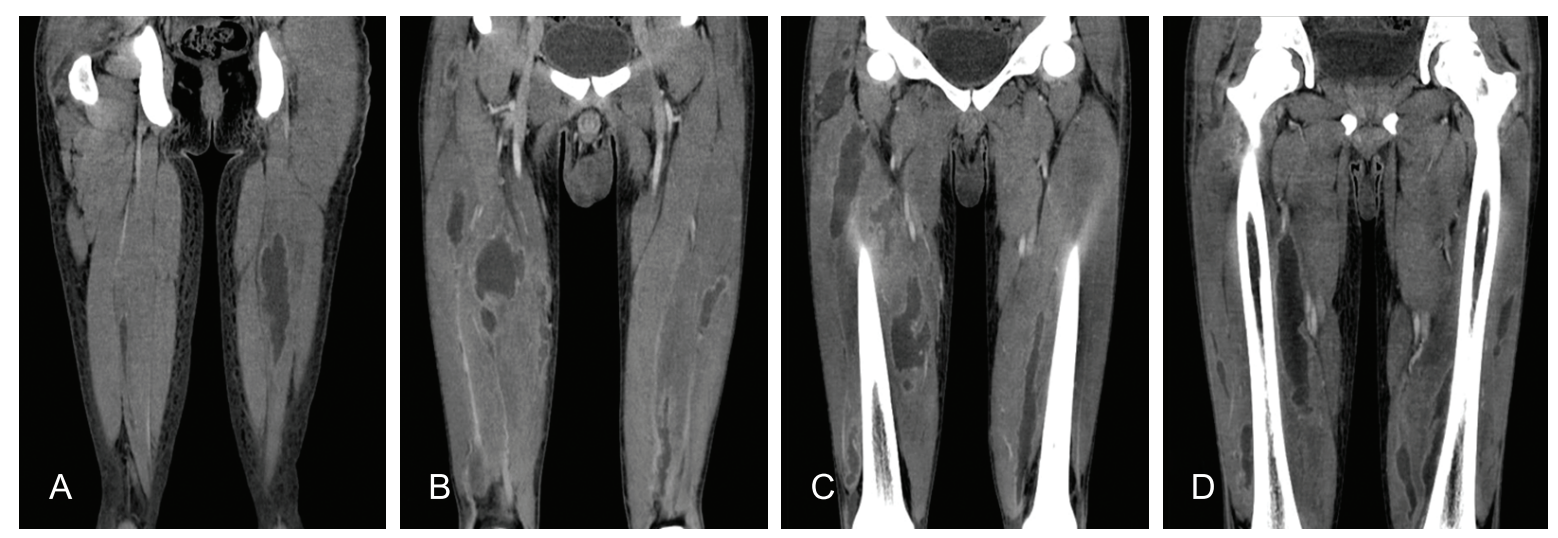

Figure 4 - Computed Tomography of the lower limbs - coronal plane. A - image compatible with abscess in the right muscle biceps femoris; B - involvement of the muscles rectus femoris and vastus lateralis (mainly on the right side); $\mathbf{C}$ and $\mathbf{D}$ - involvement of muscles: vastus medialis and vastus lateralis bilaterally. 
Among the non-specific bacteriological etiologies Staphylococcus aureus is the most common etiological agent of purulent pericarditis, accounting for $22-31 \%$ of cases according to some series. 2 Fungal infection is present in $19 \%$ of cases. Tuberculosis is another common cause however; the clinical presentation shows a subacute or chronic pattern. ${ }^{3}$

The initial evaluation of patients with suspected pericarditis should include the clinical history, physical examination focusing the search for signs of tamponade (jugular venous distention, muffled heart sounds, hypotension, and pulses paradoxus, pericardial rub), electrocardiogram, chest radiography and echocardiography. ${ }^{4}$

The electrocardiogram is the most frequently used test in the evaluation of suspected cases. The most common signs of pericarditis are diffuse ST segment elevation (typically concave up) and PR segment deviation, what means an elevation of the PR segment in lead aVR and depression of the PR segment in other limb leads and in the left chest leads V5 and V6. ${ }^{5}$ The normal echocardiogram does not exclude the diagnosis of pericarditis however, it must be requested in all cases with high suspicion of pericarditis and associated pericardial effusion, as well as signs of tamponade. ${ }^{6}$

The inflammatory process involved in the pericardium may extend to the underneath myocardium with increases in serum biomarkers of myocardial injury such as cardiac troponin and CK-MB. The high levels of these markers allow the classification of the disease as myopericarditis.

The association between pyomyositis and pyopericarditis is scarcely reported. Reports suggest that pyomyositis may be associated with pericarditis and cardiac tamponade in some cases. ${ }^{7}$ Musa et al. ${ }^{8}$ reported two cases of pyomyositis associated with pyopericarditis caused by Staphylococcus aureus and Salmonella tiphy.

The clinical manifestations of pyomyositis are fever and muscle pain, usually comprising the lower limbs. Multiple muscle groups involvement occur in in $20 \%$ of cases. ${ }^{9}$ In tropical countries, Staphylococcus aureus is implicated as the etiological agent in $90 \%$ of the cases. ${ }^{10}$ Treatment consists of antibiotic therapy plus multiple and repeated abscess drainage.
Bacterial infections are common cause of excess mortality following influenza infection, well recognized in pandemic years. Superinfections from Staphylococcus aureus following influenza are of increasing concern. This association is well established for staphylococcal pneumonia specially caused by methicillin-resistant strains. ${ }^{11}$ The patient in this report had a prior history of a viral upper airway respiratory infection with pericardial involvement. We dare assume that this viral infection could facilitate the staphylococcal infection although this association was not proved.

In the case reported here the pericardial involvement was present since the beginning of the history as well as the generalized myalgia. We assume that a staphylococcia happened after the suspected upper respiratory infection. The staphylococcal infection installed within the pericardium sac as in the striated muscle concomitantly. The pericardium involvement took the major role of the clinical picture due to the tamponade and the consequent hemodynamic collapse. When the pericardium infection seamed to be resolved the clinical picture of the pyomyositis arose.

This case highlights an atypical presentation of pyopericarditis following an upper respiratory tract infection and associated with pyomyositis. The association of bacterial pericarditis with pyomyositis is rare, whether concomitantly or in addition.

\section{REFERENCES}

1. Sagristà-Sauleda J, Barrabés JA, Permanyer-Miralda G, Soler-Soler J. Purulent pericarditis: review of a 20year experience in a general hospital. J Am Coll Cardiol. 1993;22:1661-5. http://dx.doi.org/10.1016/07351097(93)90592-O

2. Klacsmann PG, Bulkley BH, Hutchins GM. The changed spectrum of purulent pericarditis: an 86 year autopsy experience in 200 patients. Am J Med. 1977;63:666-73. http://dx.doi.org/10.1016/0002-9343(77)90150-4

3. Cegielski P, Dukes CS. Pericardial effusion in AIDS. Circulation. 1997;96:2080-1. PMid:14966036.

4. Permanyer-Miralda G. Acute pericardial disease: approach to the etiologic diagnosis. Heart. 2004;90:252-4. PMCid:1768141. http://dx.doi.org/10.1136/hrt.2003.024802

5. Imazio M, Demichelis B, Parrini I, et al. Day-hospital treatment of acute pericarditis: a management program for outpatient therapy. JAm Coll Cardiol. 2004;43:1042-6. PMid:15028364. http://dx.doi.org/10.1016/j.jacc.2003.09.055 
6. Cheitlin MD, Alpert JS, Armstrong WF, et al. ACC/AHA Guidelines for the Clinical Application of Echocardiography. A report of the American College of Cardiology/American Heart Association Task Force on Practice Guidelines. Circulation. 1997; 95:1686-744. PMid:9118558.

7. Andy JJ, Ekpo EB. Cardiovascular complications of tropical pyomiositis. Trop Geogr Med. 1987;39:260-4. PMid:3433341.

8. Musa AA, Salami BA, Tade AO. Purulent pericarditis complicating septicaemia; report of two cases. East Afr Med J. 2003;80:331-3. PMid:12953744.
9. Crum NF. Bacterial pyomyosits in the united states. Am J Med. 2004;117:420-8. PMid:15380499. http://dx.doi. org/10.1016/j.amjmed.2004.03.031

10. Christin, L, Sarosi, GA. Pyomyositis in North America: case reports and review. Clin Infect Dis. 1992;15:668-77. PMid:1420680. http://dx.doi.org/10.1093/clind/15.4.668

11. Lee $\mathrm{MH}$, Arrecubieta C, Martin FJ, Prince A, Borczuk AC, Lowy FD. A postinfluenza modelo f Staphylococcus aureus Pneumonia. J Infect Dis. 2010;201:508-15. PMid:20078212. http://dx.doi.org/10.1086/650204

\section{Conflict of interest: None}

Submitted on: $7^{\text {th }}$ February 2012

Accept on: $17^{\text {th }}$ February 2012

Correspondence: Divisão de Clínica Médica Av. Prof. Lineu Prestes, 2565 - Cidade Universitária, São Paulo/SP - Brazil CEP: 05508-000 - Phone: +55 (11) 3091-9200

E-mail: msbittencourt@bol.com.br 
